Document downloaded from:

http://hdl.handle.net/10251/48363

This paper must be cited as:

Valente Nabais, J.; Laginhas, C.; Ribeiro Carrott, MML.; Carrott, PJM.; Crespo Amorós, JE.; Nadal Gisbert, AV. (2013). Surface and porous characterisation of activated carbons made from a novelbiomass precursor, the esparto grass. Applied Surface Science. 265:919-924. doi:10.1016/j.apsusc.2012.11.164.

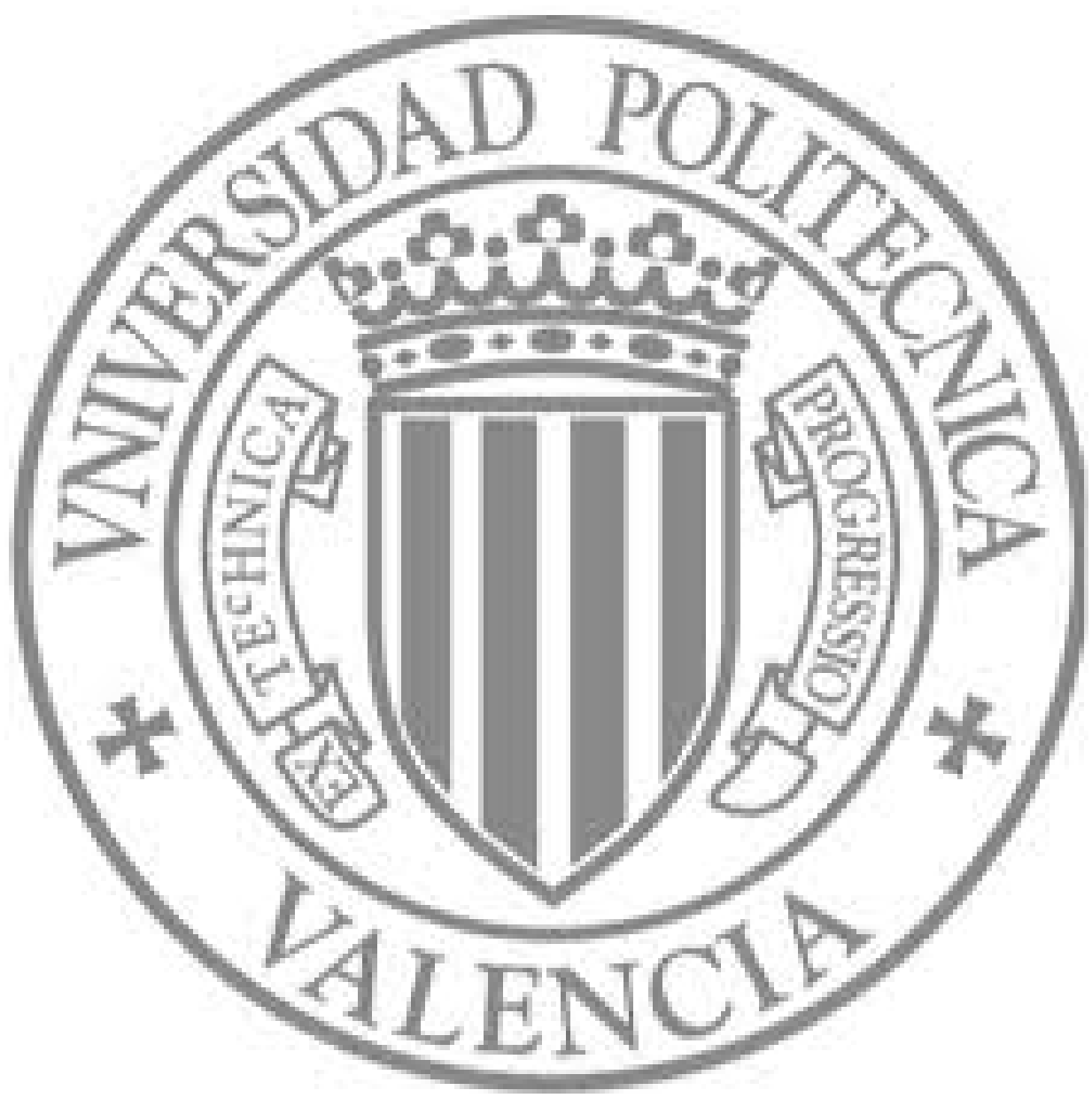

The final publication is available at

http://dx.doi.org/10.1016/j.apsusc.2012.11.164

Copyright Elsevier 


\title{
Surface and porous characterisation of activated carbons made from a novel biomass precursor, the esparto grass
}

\author{
J.M. Valente Nabais ${ }^{1 *}$, C. Laginhas ${ }^{1}$, M.M.L. Ribeiro Carrott ${ }^{1}$, P.J.M. Carrott ${ }^{1}$, \\ J.E. Crespo Amorós ${ }^{2}$, A.V. Nadal Gisbert ${ }^{2}$ \\ ${ }^{1}$ Centro de Química de Évora and Departamento de Química, Universidade de Évora, \\ Rua Romão Ramalho $n^{\circ}$ 59, 7000 - 671 Évora, Portugal. \\ ${ }^{2}$ Department of Mechanical Engineering and Materials Science, Polytechnic University \\ of Valencia, Spain.
}

\begin{abstract}
In the work now reported the production of activated carbons from a novel precursor, esparto grass, by activation with carbon dioxide is presented. The results show that the materials produced have interesting properties, namely BET apparent surface area and pore volume up to $1122 \mathrm{~m}^{2} \mathrm{~g}^{-1}$ and $0.46 \mathrm{~cm}^{3} \mathrm{~g}^{-1}$, respectively. The activated carbons have basic characteristics with point of zero charge between 9.25 and 10.27 and show a very fascinating structure, as shown by the SEM images.
\end{abstract}

Keywords: Activated carbon, esparto grass, biomass conversion, thermal treatment, nanofibers.

\section{Introduction}

Activated carbons (ACs) are used worldwide in a huge number of applications that goes from domestic to industrial uses, such as gas storage, removal of pollutants and odours, gas purification and separation, in catalysis as catalyst or catalytic support and in a number of medical uses. The ACs can be produced from a range of natural and synthetic

*Corresponding Author. Tel: +351266745318. Fax: +351266745303. E-mail address: jvn@uevora.pt (J.M.V. Nabais). 
substances, lignocellulosic materials being one of the most used precursors. The world demand for activated carbons was about 4.28 million metric tons in 2012 ? and it is expected to increase more than $10 \%$ per year over the next 5 years. This increased demand is mainly due to the more stringent pollution controls in the USA and China. For instance in China the existing plan, named the Twelfth Five-Year Plan (2011-2015), that seeks to improve the water and air quality trough the use of more environmentally friendly processes will significantly increase the activated carbon demand. Another aspect is the worldwide expanding production of edible oils, beverages and sweeteners that would consume more carbon materials [1].

Wood and coconut shell are the most used lignocellulosic materials for the production of ACs, but other agricultural by-products have also been investigated, such as date pits, palm shells, pomograde seeds, almond tree pruning, sugar cane bagasse, sunflower seed hull, olive stone, lignin, coconut shell, cherry stone and rice straws amongst others [213].

The properties of the ACs are dependent on the precursor and also on the production method used. The composition of the lignocellulosic material regarding the cellulose, hemicellulose and lignin content determines, to some extent, the porosity development of the produced ACs. The production methods reported in the literature use, amongst others, phosphoric acid $[9,11,12]$, potassium carbonate and microwave radiation $[2$, $10]$, zinc chloride $[3,8]$ and carbon dioxide $[4,6]$ as activating agents. 
Our research group has been working with a number of precursors such as cork, kenaf, rapeseed, vine shoots and coffee endocarp [14-18]. Despite the existing publications, the search for new precursors that are readily available, cheap and with good properties to be used for AC production is still one of the main research topics in this area, namely the search for materials with great valorisation potential, such as industrial and agricultural residues. The preparation of AC can be tailored for a specific application by the selection of the more suitable precursor and production method, thus the extensive publication on the production of AC with different precursors and production methods is extremely beneficial to the global community.

In this paper we report the use of a novel precursor, to the best of our knowledge never used before for the production of AC by physical activation with carbon dioxide, the esparto grass. Díaz-Teran and colleagues have previously reported the production of AC from esparto grass, but using chemical activation by impregnation of the precursor with aqueous solutions of $\mathrm{KOH}$ at different ratios and pyrolysis at 673,873 and $1073 \mathrm{~K}$ for 30 minutes [19]. The ACs produced were essentially microporous, with BET surface areas and micropore volume up to $1960 \mathrm{~m}^{2} \mathrm{~g}^{-1}$ and $0.46 \mathrm{~cm}^{3} \mathrm{~g}^{-1}$, respectively. This process is totally different from the one used by us. Activation with $\mathrm{CO}_{2}$, when compared with chemical activation, can be considered a more environmentally friendly and less expensive process, because it does not use any chemicals.

Esparto, or esparto grass, also known as needle grass (Stipa tenacissima), is a perennial grass grown in northwest Africa and the southern part of the Iberian Peninsula, which blooms between April and June. The leaves are cylindrical, tough and very tenacious 
reaching up to $1.5 \mathrm{~m}$ in height. Traditionally, esparto has been employed for crafts, such as cord and basket making. Humankind has used natural lignocellulosic materials since pre-history for an enormous amount of applications in daily life. Greek and Roman authors refer to the vast land at the Iberian Peninsula as the "Spartarion Pedion" and "Campus Spartarius" which shows that Romans used this material extensively.

\section{Materials and Methods}

\section{1 - Materials}

The precursor, esparto grass, was air dried at atmospheric conditions and used in the needle form. The esparto were cut into pieces approximately $15 \mathrm{~cm}$ long in order to get a standardized precursor dimension. About $45 \mathrm{~g}$ of precursor was weighed and put in a horizontal tubular furnace, using a suitable container, made of stainless steel with $15 \mathrm{~cm}$ length, $3 \mathrm{~cm}$ wide and $2 \mathrm{~cm}$ high. The precursor was first carbonized at $400^{\circ} \mathrm{C}$ during $1 \mathrm{~h}$, in a $\mathrm{N}_{2}$ constant flow of $85 \mathrm{~cm}^{3} / \mathrm{min}$, and then activated at $700^{\circ} \mathrm{C}$ and $800^{\circ} \mathrm{C}$, in a $\mathrm{CO}_{2}$ constant flow of $85 \mathrm{~cm}^{3} / \mathrm{min}$, for different times in order to obtain burn-offs between approximately 20 and $60 \%$ wt, switching back to the $\mathrm{N}_{2}$ flow and allowing to cool below $50^{\circ} \mathrm{C}$ before removing the AC from the furnace. The heating rate for carbonisation and activation was set at $10^{\circ} \mathrm{C} / \mathrm{min}$. The activated samples were washed in $1000 \mathrm{~mL}$ of distilled water during $24 \mathrm{~h}$ and then dried at $110^{\circ} \mathrm{C}$ for the same period. Each sample was stored in sealed flasks and identified with a code name indicating the precursor $(\mathrm{E}$, meaning esparto), the temperature of activation $\left(7\right.$ or 8 , for 700 and $800^{\circ} \mathrm{C}$, respectively) and burn-off degree. For example, sample E842 means AC with 42\%wt burn-off, produced by activation at $800^{\circ} \mathrm{C}$. 


\subsection{Characterisation}

All activated carbons were chemically and structurally characterised by infrared analysis (FTIR), elemental analysis (EA), X-ray Diffraction (XRD) and nitrogen adsorption at 77K. FTIR spectra were recorded using a Perkin Elmer model Paragon 1000PC spectrophotometer using the $\mathrm{KBr}$ disc method, 100 scans between 4000 and $450 \mathrm{~cm}^{-1}$ with $4 \mathrm{~cm}^{-1}$ resolution. The pellets were prepared using $1 \mathrm{mg}$ of AC and 500mg of $\mathrm{KBr}$ and mixing them in an agate mortar. The mixture was pressed at 10 tons for 3 min using a Specac press. The pellets were oven dried at $110^{\circ} \mathrm{C}$ during $3 \mathrm{~h}$ and then allowed to cool down in a desiccator. The Elemental Analysis was carried out in a Euro Vector Elemental Analyzer, Euro Vector Instruments. The X-Ray Diffraction patterns were obtained using a Bruker AXS-D8 Advance Powder Diffractometer equipped with a $\mathrm{CuK} \alpha$ radiation source $(40 \mathrm{kV}, 30 \mathrm{~mA})$ with wavelength of $0.150619 \mathrm{~nm}$ at a step size of $0.020^{\circ}$ between 5.000 and $60.020^{\circ}$. The nitrogen adsorption at $77 \mathrm{~K}$ was carried out in a Quadrasorb-Tri, Quantachrome Instruments. The samples were initially degassed, in a Masterprep unit, Quantachrome Instruments, at $400^{\circ} \mathrm{C}$ for a period of $4 \mathrm{~h}$, at a heating rate of $1^{\circ} \mathrm{C} / \mathrm{min}$. The precursor's cellulose and lignin content was determined by Agroleico (Porto Salvo, Portugal) using Portuguese Standards NP2029 and ME-414, respectively. The point of zero charge was determined by mass titrations as described elsewhere [20]. 


\section{Results and Discussion}

The thermogravimetric curve of the precursor is shown in figure 1. The major decomposition process occurs between 250 and $400^{\circ} \mathrm{C}$ with a weight loss of approximately $70 \%$ wt by means of two consecutive steps that according to Díaz-Terán et al. [19] is accompanied by the evolution of $\mathrm{CO}_{2}, \mathrm{CH}_{4}, \mathrm{O}_{2}, \mathrm{H}_{2} \mathrm{O}$ and $\mathrm{OH}^{-}$. The steps correspond to the decomposition of the two major components of the lignocellulosic nature of the precursor: cellulose, at lower temperatures and in a narrow range of temperatures, and lignin, over a wider range and at higher temperatures. The precursor's higher content in cellulose in comparison to lignin, indicated by the thermogravimetric curve, is confirmed by the results obtained from the laboratory analysis of the precursor, which indicated cellulose and lignin contents of 40.8 and $5.3 \% \mathrm{wt}$, respectively, as can be seen in table 1 .

Table 1. Characterisation of the precursor

\begin{tabular}{lll}
\hline & $\mathrm{C}$ & 43.62 \\
& $\mathrm{H}$ & 6.80 \\
Elemental analysis (\%wt) & $\mathrm{N}$ & 0.77 \\
& $\mathrm{~S}$ & $<\mathrm{ld}$ \\
& $\mathrm{O}^{\mathrm{a}}$ & 47.45 \\
\hline Humidity (\%wt) & 10.02 \\
\hline Ash (\%wt) & 1.36 \\
\hline Cellulose (\%wt) & 40.8 \\
\hline Lignin (\%wt) & 5.3 \\
\hline Hemicellulose (\%wt) & 53.9 \\
\hline$<$ ld - below detection limit & \\
a) By difference 100-(43.62+6.8+0.77+1.36) \\
b) By difference 100-(40.8+5.3)
\end{tabular}




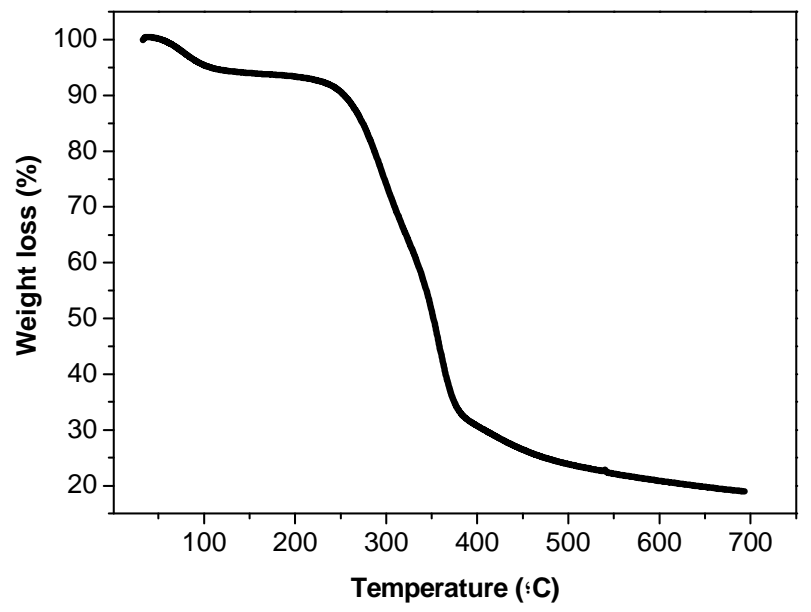

Fig. 1 - Thermogravimetric curve for Esparto Grass.

The nitrogen adsorption isotherms at 77K, shown in fig. 2(a), are of type I and of IIb, according to the IUPAC classification [21], which indicates activated carbons with porosity mainly composed of micropores. We can also observe an increase in the hysteresis loop, which is of type H3, with the burn-off value. This indicates the broadening of the pores into small mesopores, namely for samples E842, E853 and E861 (type IIb isotherms), as can also be observed in fig. 2(b) that shows the mean pore width determined by the NLDFT method, developed by Neimark and Ravikovitch [22]. The results of the isotherm analysis by the Brunauer-Emmett-Teller (BET), $\alpha_{s}$, DubininRadushkevich (DR) and NLDFT methods are given in table 2. The nitrogen adsorption for the carbonised sample was practically zero as a consequence of the porous structure being blocked by amorphous carbon. The table also shows the micropore and mesopore volume obtained from the isotherm, $\mathrm{V}_{\text {mic }}$ and $\mathrm{V}_{\text {mes }}$, namely from the adsorbed volumes at $\mathrm{p} / \mathrm{p}^{0} 0.1$ and 0.95 , respectively. The $\mathrm{V}_{\text {mic }} / \mathrm{V}_{\text {mes }}$ ratio is situated between 2 and 5 , which indicates a predominance of micropores. This observation is also corroborated by the 
data shown in fig 2(b) and by the similarity between the $V_{s}$ and $V_{0}$ values. Nevertheless, samples E724, E842, E853 and E861 show a moderate volume of mesopores close to $0.10 \mathrm{~cm}^{3} \mathrm{~g}^{-1}$. The results for the pore volume estimated by NLDFT, $\mathrm{V}_{\mathrm{DFT}}$, are in good agreement with those calculated by the $\alpha_{\mathrm{s}}$ method. The analysis of the isotherms by the different methods was done using the adsorption data that provides the best fit for each model or methodology, in particular the DR and $\alpha_{\mathrm{s}}$ were applied using the data at relative pressure of $9.0 \times 10^{-3}-2.6 \times 10^{-1}$ and $7.0 \times 10^{-1}-9.7 \times 10^{-1}$, respectively. The NLDFT method was applied to the adsorption data concerning the full range of relative pressures.

All samples have moderate external area and show, in each series, an increase in the BET surface area and micropore volume with burn-off. The samples activated at $700^{\circ} \mathrm{C}$ show a low activation rate (E726 corresponds to $7 \mathrm{~h}$ of activation) and modest porous structure, which shows the need of using temperatures higher than $700^{\circ} \mathrm{C}$ for the activation of the esparto grass with carbon dioxide. Longer activation time means also higher costs with the activation step, as it will take more carbon dioxide and more energy to obtain an interesting material. 

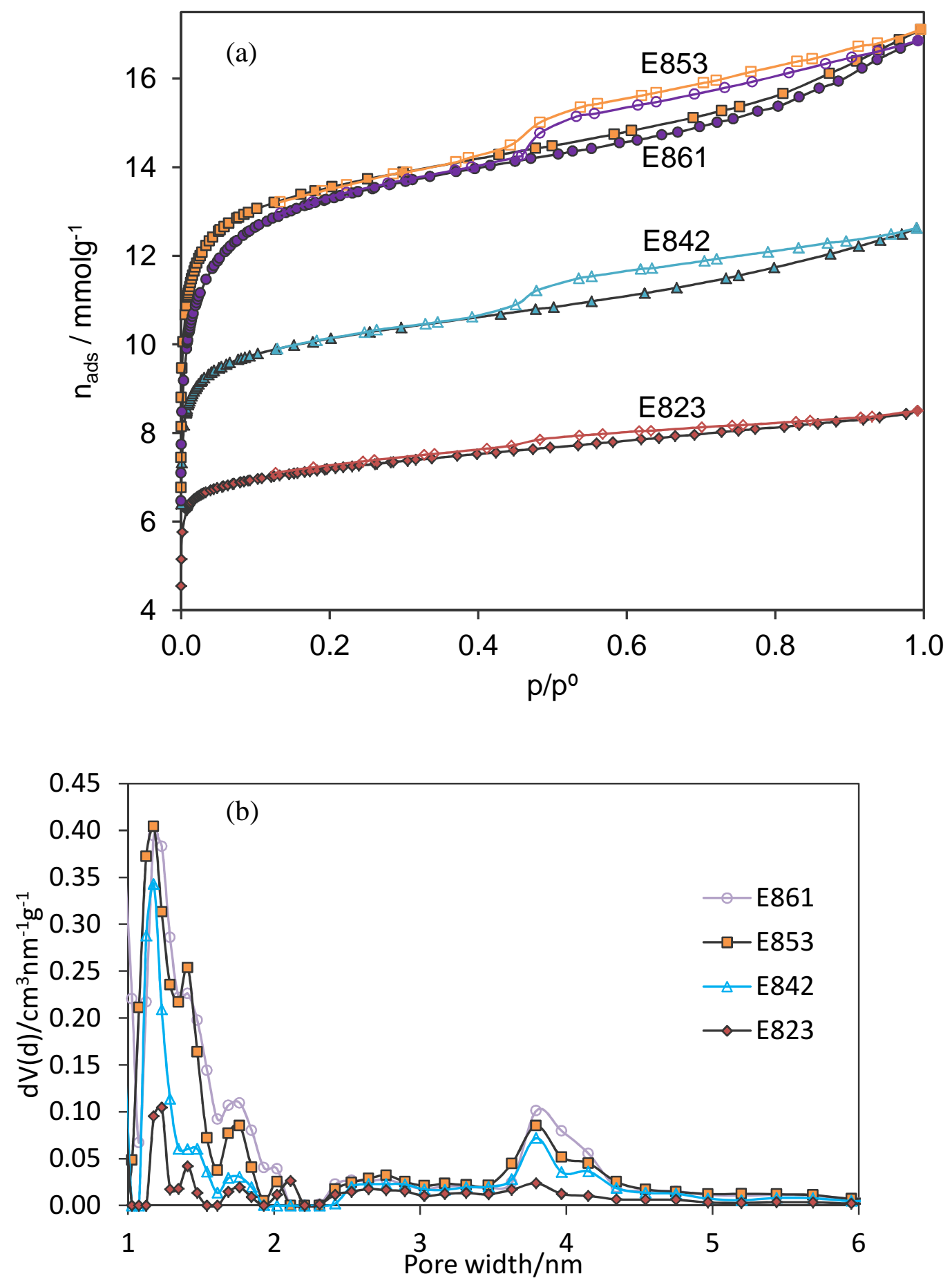

Fig. $2-\mathrm{N}_{2}$ Adsorption Isotherms at $77 \mathrm{~K}$ (a) and pore size distribution (b) for the $800^{\circ} \mathrm{C}$ series. 
Table 2. Textural and chemical characterisation of the carbon materials

\begin{tabular}{|c|c|c|c|c|c|c|c|c|c|}
\hline \multirow[b]{2}{*}{ Sample } & \multirow{2}{*}{$\begin{array}{c}\mathrm{BET} \\
\mathrm{A}_{\mathrm{BET}} \\
/ \mathrm{m}^{2} \mathrm{~g}^{-1} \\
\end{array}$} & \multicolumn{2}{|c|}{$\alpha_{\mathrm{s}}$} & \multirow{2}{*}{$\begin{array}{c}\mathrm{DR} \\
\mathrm{V}_{0} \\
/ \mathrm{cm}^{3} \mathrm{~g}^{-1}\end{array}$} & \multicolumn{2}{|c|}{ DFT } & \multirow{2}{*}{$\begin{array}{c}\mathrm{V}_{\text {mic }} \\
/ \mathrm{cm}^{3} \mathrm{~g}^{-1}\end{array}$} & \multirow{2}{*}{$\begin{array}{c}\mathrm{V}_{\text {mes }} \\
/ \mathrm{cm}^{3} \mathrm{~g}^{-1}\end{array}$} & \multirow[b]{2}{*}{$\mathrm{AT} / \mathrm{h}$} \\
\hline & & $\begin{array}{c}\mathrm{V}_{\mathrm{s}} \\
/ \mathrm{cm}^{3} \mathrm{~g}^{-1}\end{array}$ & $\begin{array}{c}\mathrm{A}_{\mathrm{ext}} \\
/ \mathrm{m}^{2} \mathrm{~g}^{-1}\end{array}$ & & $\begin{array}{l}\text { MPW } \\
/ \mathrm{nm}\end{array}$ & $\begin{array}{c}\mathrm{V}_{\mathrm{DFT}} \\
/ \mathrm{cm}^{3} \mathrm{~g}^{-1}\end{array}$ & & & \\
\hline E719 & 466 & 0.22 & 20 & 0.20 & 1.18 & 0.22 & 0.19 & 0.06 & 3 \\
\hline E724 & 603 & 0.26 & 52 & 0.24 & 0.98 & 0.30 & 0.24 & 0.11 & 5 \\
\hline E726 & 576 & 0.27 & 15 & 0.25 & 0.98 & 0.26 & 0.24 & 0.05 & 7 \\
\hline E823 & 602 & 0.27 & 16 & 0.24 & 0.94 & 0.26 & 0.24 & 0.05 & 1 \\
\hline E842 & 805 & 0.37 & 45 & 0.35 & 1.18 & 0.39 & 0.34 & 0.10 & 2 \\
\hline E853 & 1122 & 0.46 & 84 & 0.47 & 0.78 & 0.53 & 0.45 & 0.14 & 3 \\
\hline E861 & 1112 & 0.45 & 82 & 0.45 & 1.18 & 0.52 & 0.44 & 0.14 & 5 \\
\hline
\end{tabular}

MPW=Mean Pore Width, $\mathrm{A}_{\mathrm{BET}}=\mathrm{BET}$ surface area. $\mathrm{A}_{\mathrm{ext}}, \mathrm{v}_{\mathrm{s}}=$ external area and micropore volume from $\alpha_{s}$ plot. $V_{o}=$ micropore volume from DR plot. AT=activation time

As expected the reactivity of esparto at $800^{\circ} \mathrm{C}$ is much higher than at $700^{\circ} \mathrm{C}$, as can be seen in table 2. For instance, 5 hours of activation with $\mathrm{CO}_{2}$ produces samples with 24 and $61 \%$ wt burn-off, for activation at 700 and $800^{\circ} \mathrm{C}$, respectively.

The point of zero charge (pzc), which gives an evaluation of the $\mathrm{pH}$ of the materials, and the elemental analysis are shown in table 3. All activated carbon samples have basic properties, with pzc values between 9 and 10 . The basicity of the materials is in line with the FTIR analysis (representative spectra shown in fig. 3) that shows that the surface chemistry of all samples is very similar with the presence of several functional groups such as ether, phenol, carbonyl, lactones, esters and pyrones. The activated carbon samples are composed mainly by carbon and have very low nitrogen content, as indicated in table 3 . We did not detect the presence of sulfur in any of the samples. 
Table 3. Chemical and microstructure characterisation of the activated carbons

\begin{tabular}{c|c|ccc|cccc}
\hline Sample & \multirow{2}{*}{ pzc } & \multicolumn{2}{|c|}{ Elemental Composition (\%wt) } & \multicolumn{4}{c}{ XRD analysis } \\
& & $\mathrm{C}$ & $\mathrm{H}$ & $\mathrm{N}$ & $\begin{array}{c}\mathrm{d}_{002} \\
(\mathrm{~nm})\end{array}$ & $\begin{array}{c}\mathrm{L}_{\mathrm{c}} \\
(\mathrm{nm})\end{array}$ & $\begin{array}{c}\mathrm{L}_{\mathrm{a}} \\
(\mathrm{nm})\end{array}$ & $\mathrm{N}_{\mathrm{p}}$ \\
\hline E4 & 6.61 & 78.746 & 2.946 & 0.797 & 0.36 & 2.29 & 3.73 & 6.4 \\
E719 & 9.74 & 82.620 & 0.812 & 1.058 & 0.36 & 0.99 & 3.21 & 2.8 \\
E724 & 9.25 & 81.342 & 0.989 & 1.096 & 0.34 & 1.02 & 4.08 & 3.0 \\
E726 & 9.43 & 69.152 & 0.525 & 0.540 & 0.36 & 1.22 & 4.00 & 3.4 \\
E823 & 10.06 & 73.801 & 0.540 & 0.400 & 0.35 & 1.05 & 3.34 & 3.0 \\
E842 & 10.12 & 71.587 & 0.355 & 0.481 & 0.34 & 1.05 & 3.26 & 3.0 \\
E853 & 9.52 & 63.248 & 0.644 & 0.563 & 0.34 & 0.99 & 3.17 & 2.9 \\
E861 & 10.27 & 67.456 & 0.815 & 0.543 & 0.34 & 1.57 & 6.94 & 4.6 \\
\hline
\end{tabular}

pzc-point of zero charge

The FTIR spectra analysis were done using the band assignment of previous published papers [15-17, 23-25] and using the Bio-Rad $®$ "Know it All" software, which is offered by Bio-Rad to be freely used by the academic community [26]. All samples show typical absorption bands for this type of carbons. The bands at $3475-3294 \mathrm{~cm}^{-1}$ correspond to hydroxyl group $(\mathrm{v}(\mathrm{OH}))$, the presence of phenol and alcohol groups is confirmed by the bands situated at $1400-1200 \mathrm{~cm}^{-1}(\delta(\mathrm{O}-\mathrm{H}))$ and $1150-1000 \mathrm{~cm}^{-1}$ for $\mathrm{v}(\mathrm{C}-$ O). The aromatic structure of the carbons has several vibrational modes the most prominent being the bands related to $\mathrm{v}(\mathrm{C}=\mathrm{C})$, which can be found between 1600 and $1500 \mathrm{~cm}^{-1}$. Other visible bands may also be attributed to ether groups $\left(1160\right.$ and $991 \mathrm{~cm}^{-}$ ${ }^{1}, \mathrm{v}(\mathrm{C}-\mathrm{O})$ and $\mathrm{V}(\mathrm{C}-\mathrm{O}-\mathrm{C})$, respectively $)$, and ester groups $\left(1243 \mathrm{~cm}^{-1} \mathrm{v}(\mathrm{C}-\mathrm{O})\right)$. The band around $1150 \mathrm{~cm}^{-1}$ can be attributed to ether groups (vC-O). The carbonyl group can be visible in all spectra, with the presence of $(\mathrm{vC}=\mathrm{O})$ in quinones $\left(1735\right.$ and $\left.1647 \mathrm{~cm}^{-1}\right)$ and 
lactones $\left(\sim 1720 \mathrm{~cm}^{-1}\right)$. The pyrone groups can be identified by the presence of the bands at $1450-1420 \mathrm{~cm}^{-1}$, attributed to $\gamma$-pyrones $((\mathrm{vC}=\mathrm{O})$ and $(\mathrm{vC}=\mathrm{C}))$.

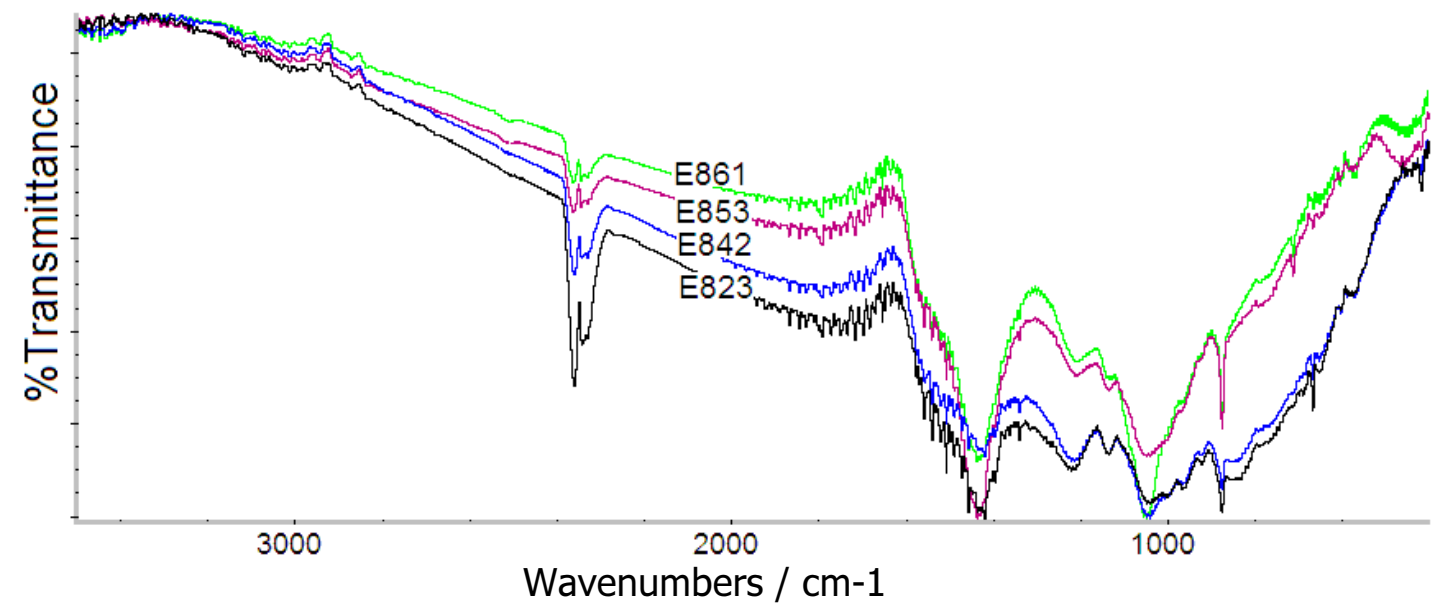

Fig. 3 - Representative FTIR spectra for samples E823, E842, E853 and E861.

Representative XRD patterns revealed in fig. 4 shows the two typical activated carbon broad bands due to reflections from the (002) and (10) planes. From the position of the (002) band we can estimate the interplanar spacing, $d_{002}$, by the application of Bragg's Law. Estimates of the mean microcrystallite dimensions, namely the height, $\mathrm{L}_{\mathrm{c}}$, and the width, $\mathrm{L}_{\mathrm{a}}$, can generally be obtained by using the Debye-Scherrer equations and the data from the bands (002) and (10), namely the position, $\theta$, and the width at half height corrected for instrumental broadening, $\beta$ (please consult reference [19] for details). The estimates of the microcrystallite mean dimensions, shown in table 3, were done by using a suitable method to determinate $\beta$ and $\theta$ values for each band corresponding to the (002) and (10) diffraction. The method has used the facilities of the software 
DIFFRACplus®, namely the smoothing of the XRD patterns by a Fourier Transform algorithm. All samples have comparable value for the interplanar spacing with medium value of $0.35 \mathrm{~nm}$. The samples activated at $700^{\circ} \mathrm{C}$ series have $\mathrm{L}_{\mathrm{c}}$ values between 0.99 and $1.22 \mathrm{~nm}$ and $\mathrm{L}_{\mathrm{a}}$ values between 3.21 and $4.00 \mathrm{~nm}$. For the $800^{\circ} \mathrm{C}$ activated samples we can observe values within the range $0.99-1.57 \mathrm{~nm}$ and 3.17-6.94 $\mathrm{nm}$ for the $\mathrm{L}_{\mathrm{c}}$ and $\mathrm{L}_{\mathrm{a}}$ values, respectively.

Besides the two mentioned broad bands we can also see in the XRD patterns other peaks corresponding to the presence of a number of heteroatoms due to inorganic oxides. We have tried to identify the type of heteroatoms present by using the best possible match between the peaks in our XRD pattern and the ones from the database of powder diffraction files included in the software DIFFRACplus®. All activated samples show consistence evidences of $\mathrm{Fe}_{3} \mathrm{O}_{4}, \mathrm{Al}_{2} \mathrm{O}_{3}, \mathrm{~K}_{2} \mathrm{O}, \mathrm{PbO}$ and $\mathrm{PbO}_{2}$.

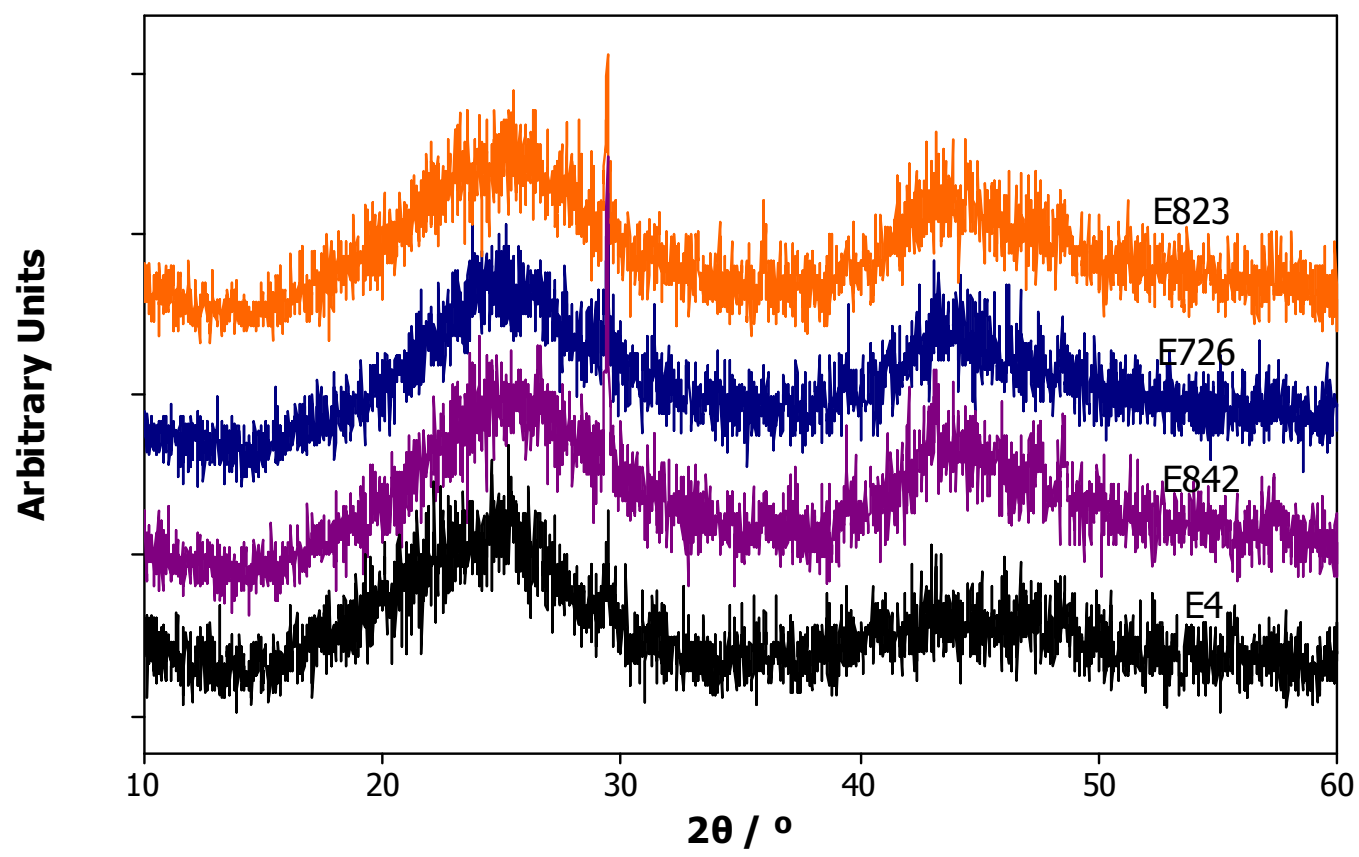

Fig. 4 - Representative XRD patterns. 
The microstructure of the activated carbons produced from esparto is very interesting, as can be seen in fig. 5. The SEM images of sample E823, used as example, show the preservation of the precursor shape after the activation. The final carbon sample is, at macroscopic scale, comparable with a small rod or cylinder with external surface shown in fig. 5 (d). Fig. 5 (a) and (b) give us an interesting perspective of the microscopic aspect of the interior part of the carbon particle, which resembles a pulmonary type structure covered by small nanofibers, shown in detail in fig. 5 (c). In conclusion, not only the macroscopic aspect is maintained but also the interior part of the precursor is directly transformed from the esparto grass to the activated carbon. The fibrous structure of the final material gives more flexibility as it can be confined and used in various forms, such as tows, fabrics and felts, which can be very useful in a number of applications such as gas masks, polarisable electrodes or dressings. 

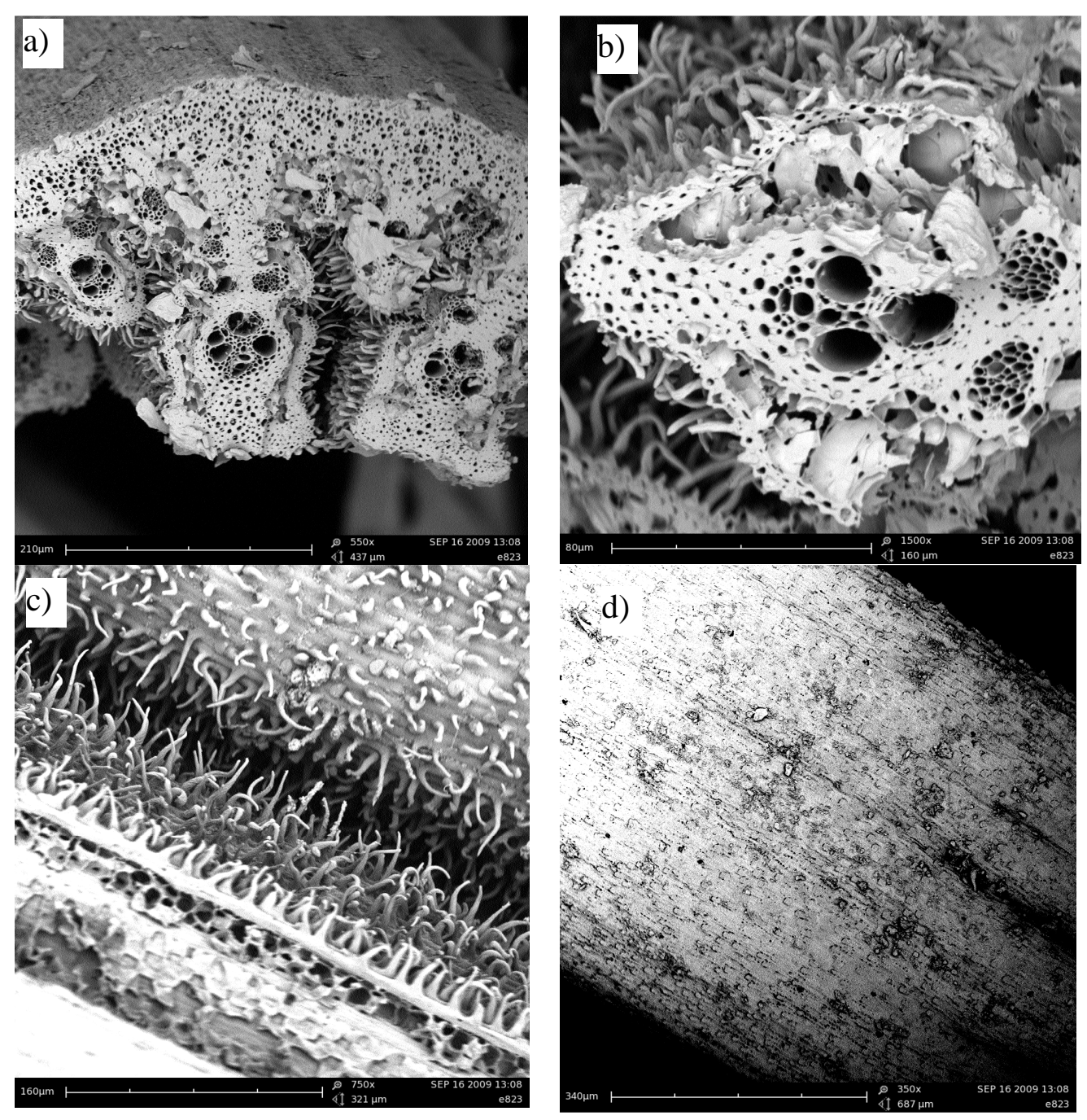

Fig. 5 - Representative SEM micrographs of sample E823, a) top view; b) detail of the "pulmonary" structure ; c) internal surface; d) external surface.

\section{Conclusions}

The results obtained allow us to conclude that esparto grass has an interesting potential for the production of activated carbons using carbon dioxide as activation agent. The carbons produced in the work now reported have interesting microstructural, chemical and textural properties with the advantage of being produced in the fibrous form, which 
opens the door to a wide range of possibilities for their application. Also, if needed, the activated carbons can be transformed into powder using regular machinery. SEM images have shown the presence of nanofibers on the interior structure of the carbons, which have origin on the precursor structure. The porosity of the produced carbons is mainly composed of micropores with BET apparent surface area and pore volume up to $1122 \mathrm{~m}^{2} \mathrm{~g}^{-1}$ and $0.46 \mathrm{~cm}^{3} \mathrm{~g}^{-1}$, respectively. The activated carbons have basic characteristics with point of zero charge between 9.25 and 10.27. The use of esparto grass for activated carbon production can create a valuable economic surplus to the farmers, which is noteworthy in such economic crisis time.

\section{Acknowledgements}

The authors are grateful to the Fundação para a Ciência e Tecnologia (Portugal) and the European Regional Development Fund (FEDER) through the Operational Programme for Competitiveness Factors (COMPETE) and QREN for financial support through Project PTDC/CTM/66552/2006 and under the Strategic Project PEstOE/QUI/UI0619/2011 (CQE/UE).

\section{References}

[1] Freedonia Report, World Activated Carbon to 2016

http://www.freedoniagroup.com/DocumentDetails.aspx?DocumentId=578390 (accessed 10 October 2012)

[2] K.Y. Foo, B.H. Hameed, Coconut husk derived activated carbon via microwave induced activation: Effects of activation agents, preparation parameters and adsorption performance, Chemical Engineering Journal 184 (2012) 57- 65.

[3] S. Uçar, M. Erdem, T. Tay, S. Karagöz, Preparation and characterization of activated carbon produced from pomegranate seeds by $\mathrm{ZnCl}_{2}$ activation, Applied 
Surface Science 255(21) (2009) 8890-8896.

[4] J. Gañán, J.F. González, C.M. González-García, A. Ramiro, E. Sabio, S. Román, Carbon dioxide-activated carbons from almond tree pruning: Preparation and characterization, Applied Surface Science 252(17) (2006) 5993-5998.

[5] Suhas, P.J.M. Carrott, M.M.L. Ribeiro Carrott, Lignin - from natural adsorbent to activated carbon: A review. Bioresource Technology 98 (2007) 2301-2312.

[6] S. Guo, J. Peng, W. Li, K. Yang, L. Zhang, S. Zhang, H. Xia, Effects of $\mathrm{CO}_{2}$ activation on porous structures of coconut shell-based activated carbons, Applied Surface Science 255(20) (2009) 8443-8449.

[7] T. Budinova, D. Savova, B.Tsyntsarski, C.O. Ania, B. Cabal, J.B. Parra, N. Petrov, Biomass waste-derived activated carbon for the removal of arsenic and manganese ions from aqueous solutions, Applied Surface Science 255(8) (2009) 4650-4657.

[8] M. Olivares-Marín, C. Fernández-González, A. Macías-García, V. Gómez-Serrano, Preparation of activated carbon from cherry stones by chemical activation with $\mathrm{ZnCl}_{2}$, Applied Surface Science 252(17) (2006) 5967-5971.

[9] B.S. Girgis , A-NA El-Hendawy . Porosity development in activated carbons obtained from date pits under chemical activation with phosphoric acid. Microporous Mesoporous Mater 52(2) (2002) 105-117.

[10] W. Li, L.B. Zhang, J.H. Peng, N. Li, X.Y. Zhu. Preparation of high surface area activated carbons from tobacco stems with $\mathrm{K} 2 \mathrm{CO} 3$ activation using microwave radiation. Ind. Crops Prod. 27 (2008) 341-347.

[11] W.C. Lim, C. Srinivasakannan, N. Balasubramanian. Activation of palm shells by phosphoric acid impregnation for high yielding activated carbon. J Anal Appl Pyrol, 88(2) (2010) 181-186. 
[12] V. Fierro, G. Muniz, AH Basta, H. El-Saied, A. Celzard. Rice straw as precursor of activated carbons: activation with orthophosphoric acid. J Hazard Mater 181(1-3) (2010) 27-34.

[13] I.I. Gurten, M. Ozmak, E. Yagmur, Z. Aktas. Preparation and characterisation of activated carbon from waste tea using K2CO3. Biomass and Bioenergy 37 (2002) 73-81.

[14] J.M.V. Nabais, C. Laginhas, P.J.M. Carrott, M.M.L. Ribeiro Carrott, Thermal conversion of a novel biomass agricultural residue (vine shoots) into activated carbon using activation with $\mathrm{CO}_{2}$, Journal of Analytical and Applied Pyrolysis, 87 (2010) 8-13. [15] J.M. Valente Nabais, J.A. Gomes, Suhas, P.J.M. Carrott, C. Laginhas, S. Roman, Phenol removal onto novel activated carbons made from lignocellulosic precursors: influence of surface properties. Journal of Hazardous Materials 167 (2009) 904-910.

[16] J.M.V. Nabais, P. Nunes, P.J.M. Carrott, M.M.L. Ribeiro Carrott, A.M. García, M.A. Díaz-Díez, Production of activated carbons from coffee endocarp by $\mathrm{CO} 2$ and steam activation. Fuel Processing Technology 89 (2008) 262-268.

[17] J.M.V. Nabais, P.J.M. Carrott, M.M.L. Ribeiro Carrott, V. Luz, A.L. Ortiz, Influence of preparation conditions in the textural and chemical properties of activated carbons from a novel biomass precursor: The coffee endocarp. Bioresource Technology 99 (2008) 7224-7231.

[18] A. Domínguez, J.A. Menéndez, Y. Fernández, J.J. Pis, J.M.V. Nabais, P.J.M. Carrott, M.M.L. Ribeiro Carrott, Conventional and microwave induced pyrolysis of coffee hulls for the production of a hydrogen rich fuel gas. Journal of Analytical and Applied Pyrolysis 79 (2007) 128-135. 
[19] J. Dáz-Terán, D.M. Nevskaia, A.J. López-Peinado, A. Jerez, Porosity and adsorption properties of an activated charcoal. Colloids and Surfaces A, 187-188 (2001) 167-175.

[20] P.J.M. Carrott, J.M.V. Nabais, M.M.L. Ribeiro Carrott, J.A. Pajares, Preparation of activated carbon fibres from acrylic textile fibres. Carbon 39 (2001) 1543-1555.

[21] J. Rouquerol, C.W. Fairbridge, D.H. Everett, J.H. Haynes, N. Pernicone, J.D.F. Ramsay, K.S.W. Sing, K.K. Unger, K.K.. Recommendations for the characterization of porous solids. Pure and Applied Chemistry 66 (1994) 1739-1758.

[22] A.V. Neimark, P.I. Ravikovitch, Capillary condensation in MMS and pore structure characterization. Microporous and Mesoporous Materials 44-45 (2001) 697-707.

[23] J.P. Villegas, C.V. Calahorro, A. Garcia, V.G. Serrano, Characterization study of char and activated carbon prepared from raw and extracted rockrose. Carbon 21 (1993) 1061-1069.

[24] J.V. Ibarra, E. Muñoz, R. Moliner, FTIR study of the evolution of coal structure during the coalification process. Org. Geochem. 24 (1996) 725-735.

[25] V.G. Serrano, J.P. Villegas, A.P. Florindo, C.D. Valle, C.V. Calahorro, FT-IR study of rockrose and of char and activated carbon. Journal of Analytical and Applied Pirolysis 36 (1996) 71-80.

[26] http://www.knowitall.com/academic/welcome.asp. (Accessed 10 May 2012). 